\title{
Caminhos investigativos nas relações entre Educação (matemática), Linguagem e Práticas Culturais
}

\author{
Carolina Tamayo ${ }^{1}$ \\ Alexandrina Monteiro ${ }^{2}$ \\ Jackeline Mendes ${ }^{3}$
}

\section{RESUMO}

A Etnomatemática, como precursora dos estudos voltados para as questões socioculturais no interior da Educação Matemática - EM, provocou um deslocamento sobre as formas de se pensar os saberes matemáticoS. Como efeito desses movimentos por nós entendido como contraconduta, iniciados pela Etnomatemática, abriram-se linhas de fuga, ampliaram-se as possibilidades para pensar a EM a partir de diferentes lentes. Nesse sentido, participantes do grupo de pesquisa interinstitucional "Educação, Linguagem e Práticas Socioculturais - PHALA" (Unicamp, USF, UFScar, UFRGS) vem há dez anos desenvolvendo pesquisas nesse campo sob diversas lentes teóricas. Diante disso, nosso objetivo neste artigo é abordar alguns dos efeitos dessas pesquisas, tanto na perspectiva pedagógica como na forma e prática de se pensar e elaborar a pesquisa acadêmica em especial aquelas inspiradas na proposta filosófica da terapia wittgensteiniana, na desconstrução derridiana e na arqueogenealogia foucaultiana. Os arquivos estudados nos permitiram identificar dois aspectos: o primeiro refere-se ao reconhecimento, da legitimidade sobre a unicidade da Matemática, a qual é fortemente questionada por esse grupo que assumiu o uso de matemáticaS,

\footnotetext{
${ }^{1}$ Doutora em Educação pela Universidade Estadual de Campinas. Professora do Grupo de Pesquisa PHALA/FE/Unicamp. Brasil. E-mail: carolina.tamayo36@ gmail.com

${ }^{2}$ Doutora em Educação pela Universidade Estadual de Campinas. Professora do Departamento Ensino e Práticas Culturais da Faculdade de Educação, Universidade Estadual de Campinas. E-mail: math_ale@uol.com.br

${ }^{3}$ Doutora em Linguística Aplicada pela Universidade Estadual de Campinas. Professora do Departamento Ensino e Práticas Culturais da Faculdade de Educação, Universidade Estadual de Campinas. E-mail: ndanda10@gmail.com
} 
no plural. E, segundo, identificamos rastros transgressores e decoloniais que emergem ao se praticar a pesquisa com estas apostas teórico-metodológicas.

PALAVRAS-CHAVE: etnomatemática, indisciplinaridade, práticas sociais, decolonialidade.

Investigative ways in the relations between (Mathematics) Education Language and Cultural Practices

\begin{abstract}
Ethnomathematics, as a precursor of studies focused on sociocultural issues within Mathematics Education (ME), has provoked a shift in the ways of thinking mathematical knowledge. As an effect of these movements understood by us as a counter-conduct initiated lines of escape which opened possibilities to think of ME from different lenses. In this sense, participants of the interinstitutional research group "Education, Language and Sociocultural Practices - PHALA" (Unicamp, USF, UFScar, UFRGS) have been developing research in this field for several years under various theoretical lenses. Therefore, our objective in this article is to discuss some of research effects in pedagogical perspective and in form and practice of thinking and elaborating academic research. Especially those inspired by wittgensteinian philosophical proposal of therapy, Derrida's deconstruction and foucaultian archeogenealogy. The studied files allowed us to identify two aspects: the first refers to the recognition of legitimacy over the uniqueness of Mathematics, which is strongly questioned by this group that assumed the use of mathematics in a plural sense. Secondly, we identify transgressive and decolonial traces that emerge when research is practiced with these theoretical-methodological bets.
\end{abstract}

KEY WORDS: Ethnomathematics; Indisciplinarity; Social Practices;

Decoloniality. 


\section{Introdução}

A Etnomatemática, como precursora dos estudos voltados para as questões socioculturais no interior da Educação Matemática (EM), provocou um deslocamento sobre as formas de se pensar as relações entre saberes a partir de práticas socioculturais. Enquanto um Programa de Pesquisa, tal como proposto por D’Ambrosio (2001), fez emergir discursos que tiveram em seu cerne o questionamento de algumas das principais estruturas do campo acadêmico da Matemática, em especial a universalidade e seu poder de emitir verdades únicas e absolutas. Esse novo lugar se organizou a partir de uma outra formação discursiva que emerge dentro do próprio campo da Matemática formal, apresentando-se como uma resistência aos modos de governamento (im)postos por esse campo. Uma resistência que não nega a Matemática e tampouco pretendeu instituir uma revolução nesse campo do saber, mas intencionou alargar as compreensões a partir de outras possibilidades de se pensar sobre fazer matemática.

Buscar novas formas de pensar os saberes, novas condutas e normas de constituição deles, é o que poderia ser visto como um movimento de contraconduta no sentido foucaultiano, discussão que será apresentada a seguir. Sua disseminação, entretanto, na medida em que abriu possibilidades de interagir com outros campos, foi ocorrendo de forma rizomática, o que nos permite compreendê-lo como um movimento múltiplo (MONTEIRO \& MENDES, 2015, 2018).

Esse movimento, em todos os seus desdobramentos, reuniu uma força motora para pensar sobre questões socioculturais no campo da pesquisa em EM o que possibilitou a abertura de interlocuções com outros campos de 
conhecimento como Antropologia Cultural, Sociologia, Filosofia e Linguística, entre outros.

Nos diversos campos que se moveram para esse enfoque sociocultural no âmbito da pesquisa em EM a questão da centralidade da linguagem entrou em cena para problematizar relações entre saberes, práticas e sujeitos. Foi nesse movimento que se configurou o Grupo "Educação, Linguagem e Práticas Socioculturais-PHALA"4 da Universidade Estadual de Campinas (Brasil, SP), por uma preocupação comum manifestada nos trabalhos de pesquisa e docência de professores de diferentes instituições de ensino superior: Universidade Estadual de Campinas (UNICAMP), Universidade Federal de São Carlos (UFSCAR), Universidade São Francisco (USF) e Universidade Federal do Rio Grande do Sul (UFRGS). A compreensão de que a problematização da relação entre linguagem e práticas culturais poderia representar um avanço nos modos de se pensar a educação escolar e a formação de professores, seja no âmbito da ação pedagógica, seja no âmbito da pesquisa acadêmica, foi se configurando como base de diálogo entre esses professores, mesmo considerando a diversidade de seus campos de investigação. Mais especificamente, foi se evidenciando um interesse em torno da repercussão da virada linguística e do pressuposto do papel constitutivo da linguagem sobre as formas de se conceber a subjetividade, as práticas culturais, as atividades humanas, a formação de professores, dentre outros, bem como sobre a exploração de novos referenciais metodológico-conceituais para a pesquisa em educação.

Deste modo, o grupo PHALA vem desenvolvendo estudos ao nível de doutorado, mestrado e projetos pesquisa e de extensão orientados pelos modos de pensar e fazer seus trabalhos com base nas perspectivas das filosofias: da diferença de Deleuze; da terapia desconstrutiva de Wittgenstein e Derrida e da

\footnotetext{
${ }^{4}$ Link oficial do grupo PHALA: https://www.phala.fe.unicamp.br/
} 
arquegenealogia foucaultiana, procurando transgredir, a partir da virada linguística, a matriz epistemológica ocidentalizada 5 sobre o qual o pensamento Matemático moderno foi construído.

Assim, consideramos importante caracterizar alguns dos efeitos provocados pelos modos em que o grupo PHALA vem praticando a pesquisa no campo da Educação, mais especificamente no campo da EM, para isto, apresentaremos algumas produções do grupo como arquivos ${ }^{6} \operatorname{como}_{\text {base }}$ documental 7 , procurando entender os seus efeitos como possibilidades de linhas de fuga para a criação de modos outros de se produzir pesquisas no campo de EM com base numa perspectiva filosófica caracterizada pela inversão e deslocamento 8 buscando romper com a concepção representacionista da linguagem.

Para os propósitos deste artigo, tomamos alguns dos arquivos produzidos nos últimos 10 anos, especialmente teses de doutorado e dissertações de mestrado, arquivos que em sua espectralidade são por nós considerados na sua fantasmagoria, provocadores de efeitos de sentido num devir-fantasma que os constitui, mas,

Porque insistir aqui na espectralidade? [...] Sem dúvida, mas principalmente, porque a estrutura do arquivo é espectral. Ela o é a

\footnotetext{
${ }_{6}^{5}$ De carater prescritvo que sustenta dicotomias como: corpo/mente, exterior/interior, natureza/cultura, entre outros.

${ }^{6}$ Em Mal de Arquivo: uma impressão freudiana (2001), obra publicada em francês em 1995, Derrida irá discutir a dificuldade de se trabalhar com o conceito de arquivo procurando deslocar (pela desconstrução) o processo de arquivamento como algo fechado. Sua principal crítica é à redução do arquivo a uma experiência da memória, ao retorno da origem, ao arcaico (de arkhé) e ao arqueológico, à lembrança ou à escavação. Deste modo, Derrida chama a atenção para o fato de um arquivo não pode ser reduzido a uma massa documental fixa e cristalizada, significando apenas referência temporal ao registro do passado. Não seria apenas reflexo do que ocorreu de fato, como experiência histórica. Um arquivo não se reduz a um depósito de memórias sem rasuras, não lacunar, sem esquecimento, bastando acioná-lo para que todas as representações ali guardadas possam vir à tona. O arquivo é, pois, o lugar da gestão da memória, mas também o campo do esquecimento.

${ }^{7}$ Destacamos que o recorte aqui realizado não considerou trabalhos mais recentes que envolvem a filosofia da diferença de Deleuze

${ }^{8}$ No sentido de Derrida (2004).
} 
priori: nem presente nem ausente "em carne e osso", nem visível nem invisível, traço remetendo sempre a um outro cujo olhar não saberia ser cruzado, não menos que, graças à possibilidade de uma viseira, o fantasma do pai de Hamlet. Pois o motivo espectral põe bem em cena esta fissão disseminam-te que afeta desde o princípio, o princípio arcôntico, o conceito de arquivo e o conceito em geral. (DERRIDA, 2001, p. 110-111)

Textos vistos não apenas como escrituras do passado, mas também como estruturas do presente que se abrem para o futuro numa repetição, arquivos no seu devir-fantasma, provocadores de contracondutas e de novos fluxos (DELEUZE \& GUATTARI, 1995), novos afetos. Vale a pena notar que de fato, não iremos a retomar, para efeitos de análise, nem todas as pesquisas desenvolvidas pelo grupo nem todos os artigos acadêmicos produzidos nos últimos anos, contudo, o arquivo constituído faz surgir uma multiplicidade de enunciados e efeitos de sentido que é o que nos interessa, um arquivo que sem tempo nem lugar, entre a tradição e o esquecimento, faz aparecerem os modos em que o grupo PHALA vem traçando percursos investigativos que operam outros modos de pensar relações entre Educação, Linguagem e Práticas Culturais, num movimento de decolonização $o^{9}$ do pensamento.

Nos propomos a percorrer estes arquivos não para estabelecer balizas que determinem formas de se praticar a pesquisa, mas procurando efeitos de sentidos ao descrever aspectos e rastros dessas produções acadêmicas orientadas pelos modos de pensar a filosofia da terapia wittgensteiniana, da

\footnotetext{
9 O uso dos termos 'decolonialidade' e ‘decolonização do pensamento' está em consonância com o movimento de pensamento de autores latino-americanos que vêm problematizando as relações de colonialidade na América Latina, a partir de discussões em torno de geopolíticas do conhecimento e dos processos de colonialidade do poder e do saber (CASTRO-GOMES \& GROSFOGUEL, 2007).
} 
desconstrução derridiana e da arquegenealogia foucaultiana para desenvolver pesquisas em EM, numa perspectiva sociocultural.

Assim, nosso ponto de partida é propor um debate dessas produções do grupo a partir de um exercício documental procurando rastros dos efeitos de se práticar a pesquisa com uma atitude espectral10. Por outro lado, atentamos para a questões de ordem epistemológicas dessas produções, procurando entender os efeitos de estudar as formas de produção dos conhecimentos matemáticoS com foco nas práticas socioculturais presentes em diversas formas de vida, tal e como elas são nelas praticadas. Na tabela 1 apresentamos as produções, e os seus objetivos, elencadas para comporem o arquivo para as discussões que serão mobilizadas nesse artigo:

Tabela 1. Arquivos das produções do grupo PHALA foco deste artigo.

\begin{tabular}{|l|l|l|}
\hline \multicolumn{1}{|c|}{ Autor/año } & \multicolumn{1}{|c|}{ Titulo } & \multicolumn{1}{c|}{ Propósito da investigação } \\
\hline $\begin{array}{l}\text { VILELA } \\
(2007)\end{array}$ & $\begin{array}{l}\text { Matemáticas nos Usos } \\
\text { e Jogos de Linguagem: } \\
\text { ampliando concepções } \\
\text { na } \\
\text { matemática. }\end{array}$ & $\begin{array}{l}\text { “..a pesquisa se iniciou observando os usos que } \\
\text { têm sido feitos da expressão matemática nas } \\
\text { publicaçôes e pesquisas recentes em Educação } \\
\text { Matemática. Em consonância com a perspectiva } \\
\text { filosófica aqui adotada, optamos por perguntar: } \\
\text { Como o termo 'matemática' vem sendo usado na } \\
\text { literatura acadêmica da Educação Matemática?" } \\
\text { (p. 6). }\end{array}$ \\
\hline BELLO (2011) & $\begin{array}{l}\text { Jogos de Linguagem, } \\
\text { práticas discursivas e e } \\
\text { produção de verdade: } \\
\text { contribuições para a aste artigo tem por objetivo trazer alguns dos } \\
\text { desdobramentos que as denominadas "teorizações } \\
\text { pós-estruturalistas" trazem ao campo da filosofia } \\
\text { contemporânea, especificamente, aqueles que }\end{array}$ \\
\hline
\end{tabular}

\footnotetext{
${ }^{10}$ No livro Espectros de Marx o filósofo franco-argelino Jacques Derrida (1994), descreve a espectralidade e sua importância na atitude da desconstrução por ele praticada, partindo da experiência do inelidível dos rastros nos processos de produção de sentidos, isto é, nem presença e nem a ausência plena de uma significação das palavras, uma vez que estas são só os rastros que se deslocam e se iteram mediante rastros e rastros do apagamento de rastros. Deste modo a espectralidade é um indecidível, nem presença e nem ausência e ao desconstruir essa oposição, põe em cena uma outra "lógica": a de um pensamento não orientado pela fixação de sentidos, em outras palavras "o espectro é, em primeiro lugar, do visível. Mas é do visível invisível, da visibilidade de um corpo que não está presente em carne e osso. Ele se recusa à intuição [...] a qual ele se dá, ele não é tangível. [...] E o que acontece com a espectralidade, com a fantasmalidade [...] é que ela torna quase visível o que não é visível a não ser que não se veja em carne e osso. É uma visibilidade da noite. Logo que haja tecnologia da imagem, a visibilidade carrega a noite, ela encarna em um corpo de noite, ela irradia uma luz noturna. (DERRIDA \& STIEGLER 2002,115).
} 


\begin{tabular}{|c|c|c|}
\hline & $\begin{array}{l}\text { Educação (Matemática) } \\
\text { contemporânea }\end{array}$ & $\begin{array}{l}\text { dizem respeito ao papel da linguagem na } \\
\text { constituição das práticas e das relações sociais; } \\
\text { bem como o exercício do poder na produção de } \\
\text { verdades, de saberes e de sujeitos. Assim, com } \\
\text { base nas noções wittgensteinianas de jogos de } \\
\text { linguagem e nas noções foucaultianas de prática } \\
\text { discursiva; poder-saber; e jogos de verdade, } \\
\text { perpassados por algumas ideias de cunho } \\
\text { nietzschiano, discutem-se alguns entendimentos } \\
\text { sobre a Matemática e a prática pedagógica como } \\
\text { atividades regradas, a produção de saberes e } \\
\text { verdades como exercício de poderes e a } \\
\text { constituição/fabricação dos sujeitos da educação: } \\
\text { professor, aluno. Esses entendimentos e suas } \\
\text { problematizações são trazidos dentro desta } \\
\text { analítica, por considerá-las importantes aos modos } \\
\text { de dizer e ver a Educação (Matemática) } \\
\text { contemporânea" (p, 1) }\end{array}$ \\
\hline $\begin{array}{l}\text { MIGUEL, et } \\
\text { al. }(2011)\end{array}$ & $\begin{array}{l}\text { Desconstruindo a } \\
\text { matemática escolar sob } \\
\text { uma perspectiva pós- } \\
\text { metafísica de educação }\end{array}$ & $\begin{array}{l}\text { "Neste artigo, que se desenvolve no âmbito da } \\
\text { filosofia da educação matemática, estabelecemos } \\
\text { diálogo com perspectivas discursivas pós } \\
\text { metafísicas constituídas, sobretudo, nos campos } \\
\text { da filosofia e da linguística aplicada. O nosso } \\
\text { propósito é investigar estratégias que poderiam } \\
\text { viabilizar e dar visibilidade a uma perspectiva } \\
\text { transgressiva de ação educativa escolar. Tal } \\
\text { perspectiva se pauta em uma ética política } \\
\text { desconstrutiva que se desenvolve através da } \\
\text { realização do que estamos aqui denominando } \\
\text { práticas (in)disciplinares de problematização } \\
\text { cultural. Essa problematização incide sobre duas } \\
\text { questôes centrais, a saber: a desconstrução da } \\
\text { matemática como disciplina escolar e a } \\
\text { desconstrução da concepção de educação escolar } \\
\text { como transmissão ou apropriação individual de } \\
\text { conhecimentos disciplinares". (p, 129) }\end{array}$ \\
\hline $\begin{array}{l}\text { LAZARA } \\
(2012)\end{array}$ & $\begin{array}{l}\text { Gracejos e Artimanhas } \\
\text { como jogos discursivos } \\
\text { na Feira Livre: } \\
\text { contribuições para } \\
\text { pensar a aprendizagem } \\
\text { nas práticas sociais de } \\
\text { venda e compra }\end{array}$ & $\begin{array}{l}\text { "A feira livre pode ser entendida na } \\
\text { contemporaneidade como um espaço social- } \\
\text { educativo não formal, organizada por diferentes } \\
\text { práticas e saberes. Desse modo, o presente } \\
\text { trabalho discute como se engendram esses saberes } \\
\text { no contexto da feira livre, tomando como eixo } \\
\text { norteador as relações de poder"saber (Michel } \\
\text { Foucault) nas práticas discursivas que compoem } \\
\text { os processos de compra e venda na feira, a partir } \\
\text { de diversos jogos para promover a integração, }\end{array}$ \\
\hline
\end{tabular}




\begin{tabular}{|c|c|c|}
\hline & & $\begin{array}{l}\text { interação e o convencimento nos processos de } \\
\text { compra e venda. Outro fator significativo é } \\
\text { entender como são produzidas essas práticas } \\
\text { específicas da feira livre no interior dos modos } \\
\text { capitalistas e da globalização que regem as a } \\
\text { relaçốs sociais, políticas e econômicas no mundo } \\
\text { contemporâneo". (p, } 7 \text { ) }\end{array}$ \\
\hline $\begin{array}{l}\text { NAKAMURA } \\
(2014)\end{array}$ & $\begin{array}{l}\text { Problematização } \\
\text { indisciplinar de } \\
\text { práticas socioculturais } \\
\text { na formação inicial de } \\
\text { professores. } 2014 .\end{array}$ & $\begin{array}{l}\text { "Compreender que usos estudantes-futuros } \\
\text { professores fazem da problematização } \\
\text { indisciplinar de práticas socioculturais em seus } \\
\text { campos de estágio elou em uma disciplina do } \\
\text { curso de Pedagogia; mais especificamente, que } \\
\text { usos da relação teoria-prática são mobilizados } \\
\text { neste contexto" (p. 6). }\end{array}$ \\
\hline $\begin{array}{l}\text { ALVES } \\
(2014)\end{array}$ & $\begin{array}{l}\text { O papel dos } \\
\text { conhecimentos } \\
\text { valores transmitidos } \\
\text { pela escola, na } \\
\text { construção de mundo } \\
\text { de uma comunidade } \\
\text { caiçara do Rio de } \\
\text { Janeiro. }\end{array}$ & $\begin{array}{l}\text { "Problematizar, através de uma visão terapêtica } \\
\text { Wittgensteiniana, os significados da escola, para } \\
\text { uma comunidade caiçara localizada em uma } \\
\text { reserva ecológica no sul do Estado do Rio de } \\
\text { Janeiro"(p.6). }\end{array}$ \\
\hline $\begin{array}{l}\text { MIGUEL } \\
(2015)\end{array}$ & $\begin{array}{l}\text { A Terapia Gramatical- } \\
\text { Desconstrucionista } \\
\text { como Atitude de } \\
\text { Pesquisa } \\
\text { (Historiográfica) em } \\
\text { Educação (Matemática) }\end{array}$ & $\begin{array}{l}\text { "Partindo da polêmica metodológica que se } \\
\text { estabeleceu, a partir da crítica desconstrucionista } \\
\text { feita por Jaques Derrida ao livro A história da } \\
\text { Loucura de Michel Foucault, no início da década } \\
\text { de 1960, temos como propósito, neste artigo, } \\
\text { caracterizar o que temos denominado "terapia } \\
\text { gramatical desconstrucionista" como uma atitude } \\
\text { pós-estruturalista de investigação acadêmica no } \\
\text { campo da (historiografia da) educação } \\
\text { (matemática), mas cujo domínio de aplicação pode, } \\
\text { pensamos, se estender à Educação, às Artes ou, } \\
\text { mais amplamente, às Humanidades. Essa atitude } \\
\text { tem como principais referências os trabalhos de } \\
\text { dois destacados filósofos do século XX: Ludwig } \\
\text { Wittgenstein e Jacques Derrida". (p. } 607 \text { ) }\end{array}$ \\
\hline $\begin{array}{l}\text { TAMAYO- } \\
\text { OSORIO } \\
(2017)\end{array}$ & $\begin{array}{l}\text { Vení, vamos hamacar } \\
\text { el mundo, hasta que te } \\
\text { asustes: uma terapia do } \\
\text { desejo de escolarização } \\
\text { moderna }\end{array}$ & $\begin{array}{l}\text { "O propósito que orientou a escrita da tese foi o de } \\
\text { descrever terapeuticamente aspectos do desejo de } \\
\text { escolarização moderno a partir das diferentes } \\
\text { significações que eles apresentam, tanto para a } \\
\text { Comunidade indígena Gunadule de Alto Caimán } \\
\text { (Colômbia) - junto à qual realizamos o trabalho de } \\
\text { campo que orienta a referida descrição terapêutica }\end{array}$ \\
\hline
\end{tabular}




\begin{tabular}{|c|c|c|}
\hline & & $\begin{array}{l}\text {-, quanto para outras formas de vida a que fomos } \\
\text { remetidos no percurso investigativo" (p. 10) }\end{array}$ \\
\hline $\begin{array}{l}\text { MONTEIRO } \\
\& \text { MENDES } \\
(2015,2018)\end{array}$ & $\begin{array}{l}\text { Etnomatemática como } \\
\text { Movimento de } \\
\text { Contraconduta na } \\
\text { Mobilização de Saberes } \\
\text { em Práticas Culturais. } \\
\text { Movimento de contra- } \\
\text { conduta na mobilização } \\
\text { de saberes em práticas } \\
\text { culturais no campo da } \\
\text { Educação Matemática. }\end{array}$ & $\begin{array}{l}\text { Esses textos têm por objetivo discutir o campo da } \\
\text { Etnomatemática a partir de pesquisas e estudos } \\
\text { que mostram a diversidade de entendimento desse } \\
\text { movimento no interior do campo da Educação } \\
\text { Matemática. Pretendemos problematizar e } \\
\text { analisar esse movimento a partir de uma } \\
\text { perspectiva foucaultiana, a partir do conceito de } \\
\text { contraconduta. A importância dessa discussão se } \\
\text { amplia pelos usos e apropriações que são feitos por } \\
\text { essas discussões - em especial em documentos de } \\
\text { políticas públicas as quais tendem a desviar o foco } \\
\text { e as ideias que transitam por esse movimento. } \\
\text { Nossa discussão irá considerar propostas de } \\
\text { pesquisas e estudos que se sobressaíram ao longo } \\
\text { desse movimento que vem se fortalecendo desde a } \\
\text { década de 1980. Nossa compressão é que sua } \\
\text { disseminação foi ocorrendo de forma rizomática, o } \\
\text { que nos permite compreendê-lo como um } \\
\text { movimento múltiplo. Assim, } \\
\text { discussão/apresentação pretende problematizar } \\
\text { aspectos dessa multiplicidade de propostas por } \\
\text { vezes antagônicas considerando o fato de sua raiz } \\
\text { emergir no interior do campo estruturalista da } \\
\text { Matemática. (p.1) }\end{array}$ \\
\hline
\end{tabular}

A identificação dos objetivos destes trabalhos levou-nos a desenvolver uma leitura cuidadosa de cada um, nos permitindo identificar semelhanças de rastros nos arquivos sob dois aspectos: o primeiro refere-se ao reconhecimento, legitimação e questionamento da forma de se compreender a Matemática como um conjunto de saberes limitados a sua organizaão hierárquica disciplinar, tomando como campo de investigação várias formas de vida. E, segundo, identificamos rastros dos efeitos de praticar a pesquisa de forma decolonial no campo da EM, a partir de uma perspectiva sociocultural como condutas outras para se investigar problemas no campo da Educação. Estes dois aspectos são vistos, a partir de nossa perspectiva, como as apostas epistemológicas e teóricometodológicas presentes nos caminhos investigativos dessas produções que são 
uma pequena amostra das pesquisas desenvolvidas no grupo de pesquisa PHALA.

\section{Apostas epistemológicas: alguns efeitos dos caminhos investigativos}

Os arquivos que retomamos para esta escrita mobilizam práticas e discursos de diversos campos de atividade, como por exemplo, ensino de matemática na educação básica, comunidades indígenas, filosofia da educação matemática, práticas de compra e venda na feira livre; práticas relacionadas aos usos e sentidos do tempo a partir da observação do céu; assim, estas pesquisas compõem um acervo de registros de diversas práticas sociais ao estudarem diversas formas de vida, o que possibilita uma visão panorâmica dos desdobramentos desses arquivos, não apenas em relação aos modos mais usuais em que usamos em jogos matemáticoS de linguagem ${ }^{11}$, mas também em relação às problematizações dos usos que dela se fazem em formas de vida mais especializadas, tais como aquelas mantidas por Matemáticos, educadores Matemáticos ou filósofos da Matemática.

Esses caminhos trilhados nas pesquisas a respeito das formas de produção, validação e legitimação dos conhecimentos matemáticoS são encarados pelos pesquisadores como condutas outras, isto é, efeitos das linhas de fuga que se tem possibilitado no campo da EM pelas trilhas que a Etnomatemática tem provocado ao pensar educações matemáticaS outras.

\footnotetext{
${ }^{11}$ Para Wittgenstein, um jogo de linguagem é sempre um jogo situado de performance corporal dos jogadores que, nele, interagem entre si, isto é, "chamarei de jogos de linguagem o conjunto da linguagem e das ações com as quais está interligada" (Wittgenstein, 1999, p. 8). Nesse sentido, ver as matemáticaS, como nós a temos visto, a partir de Wittgenstein, não como um domínio unitário de conhecimentos disciplinarmente organizado, mas como um conjunto ilimitadamente discreto de jogos normativamente regrados de linguagem, nos leva a confrontar diretamente a unicidade da Matemática. Isto é, em palavras de MIGUEL (2016, p. 340), “participar de jogos normativamente regrados de linguagem, isto é, fazer matemática, é também permitir que nossos corpos se deixem governar pelas regras, algoritmos ou scripts desses jogos para que possamos atingir os propósitos sociais por eles visados".
} 
O sentido de condutas outras que estamos mobilizando é proveniente da noção foucaultiana de contraconduta. Foucault (2008, p. 271) propõe o emprego da palavra "contraconduta" no sentido de "luta contra os procedimentos postos em prática para conduzir os outros". Para Candiotto (2010, p. 10) esse sentido abre "a possibilidade (do sujeito) atuar como agente da própria subjetivação a partir de outro modo de condução que não aquele da obediência integral e incondicional" à qual está submetido. Assim os movimentos de contraconduta teriam como objetivo outra conduta:

Querer ser conduzido de outro modo, por outros condutores e por outros pastores, para outros objetivos e para outras formas de salvação, por meio de outros procedimentos e de outros métodos", seriam formas de "escapar da conduta dos outros", procurando "definir para cada um a maneira de se conduzir". (FOUCAULT, 2008, p.287).

A partir dessa noção é possível reconhecer a Etnomatemática como um movimento de contraconduta no interior do campo do saber da Matemática. Um movimento marcado por se opor a uma metanarrativa pautada em uma racionalidade de tradição filosófica transcendental e essencialista que coloca a Matemática como única e independente de qualquer contexto sociocultural. Posto de outro modo, a Etnomatemática aparece como uma contraconduta por não romper nem com a estrutura da Matemática e nem mesmo se colocar contra os princípios desse campo do saber, mas por reclamar outra forma de pensar e de se fazer matemática (MONTEIRO; MENDES, 2015, 2018). E, os rastros dessa contraconduta criam novas possibilidades de se pensar matematicamente, compreendendo, neste caso, os saberes como possibilidades de criação e não de reprodução, como pensamentos outros, matemáticaS outras. 
Este movimento, que não se dá precisamente de forma linear nos arquivos, o caracterizamos como pós-epistemológico ao provocar a expansão dos usos e os significados da Matemática para as matemáticaS a partir do estudo das práticas ${ }^{12}$ tal e como são realizadas em contextos específicos de atividade, como Vilela (2007, p. 19-20) aponta,

Quando se afirma ou se pergunta sobre a unicidade da matemática, afirmá-la ou negá-la pode ser dogmático, enquanto que perceber as especificidades em que conceitos matemáticos ou a palavra matemática são usados nos possibilita falar de vários jogos de linguagem condicionados por regras próprias, além das possíveis semelhanças. Associamos esta mudança de referência - da Matemática para as matemáticas- ao que chamamos de Revolução copernicana na Educação matemática, expressão adaptada ao contexto de nossa pesquisa a partir da expressão Copernican social science revolution (RESTIVO, 1993, p. 248).

O rompimento com a naturalização da unicidade da Matemática ao se falar, de fato, em matemáticaS no plural, está relacionado ao fato de estudar as práticas socioculturais procurando olhar para elas como jogos de linguagem que muitas vezes nada tem a ver com os jogos de linguagem da Matemática acadêmica, toda vez que, partimos da compreensão de que uma prática não só é um conjunto ordenado, regrado e intencional de ações físicas, mas também, um lugar onde ações são realizadas com propósitos inequívocos e de forma indisciplinar. Deste modo, os arquivos provocam novos (DES)afetos ao mostrar

\footnotetext{
${ }^{12}$ Vale pena notar que nos arquivos que estão sendo estudados para compor este texto, se compreende por práticas ao conjunto de ações; ou ainda, procedimentos orientados normativamente em uma determinada forma de vida com o objetivo de alcançar uma finalidade, em outras palavras "[...] toda ação ou conjunto intencional e organizado de ações físico-afetivo-intelectuais realizadas, em um tempo e espaço determinados, por um conjunto de indivíduos, sobre o mundo material e/ou humano e/ou institucional e/ou cultural, ações essas que, por serem sempre, em certa medida e por um certo período de tempo, valorizadas por determinados segmentos sociais, adquirem uma certa estabilidade e realizam-se com certa regularidade[...].” (MIGUEL, VILELA e MOURA, 2008, p. 27).
} 
desvios opcionais nas trilhas para se estudar formas de produção de conhecimentos matemáticos, como,

uma rota para lutarmos contra o poder de "enfeitiçamento" disciplinar de ver as matemáticas exclusivamente como um conjunto fixo de conteúdos conceituais típicos - abstratos e genéricos - envolvendo números, medidas, formas geométricas definidas, etc., conformados em um domínio compartimentado e especializado do saber, e que também nos impede de vê-las envolvidas em práticas socioculturais de qualquer natureza realizadas nos contextos de diferentes atividades humanas, forma esta de ver que, para nós, constitui o ponto de inflexão desconstrutivo relativo a concepções de matemática sugerido pelo pensamento do último Wittgenstein. (MIGUEL, 2015, p. $150)$.

É preciso esclarecer, que as pesquisas analisadas inspiradas nos trabalhos do último Wittgenstein (1999) e de Derrida (2002), não têm a pretensão de delimitar uma significação essencial de Matemática, ou um único uso das matemáticaS, que atravesse todos os jogos de linguagem existentes em todas as formas de vida, toda vez que, isto, contraria os propósitos destes trabalhos. Assim, estas investigações voltam seus olhares para as práticas culturais procurando estudá-las na forma em que são praticadas.

Ao estudar as práticas culturais as pesquisas não ás comparam com uma suposta Matemática universal, com o objetivo de identificar como essa Matemática acontece nessas práticas. Se evidencia que o propósito, é pensar sobre as mobilizações de saberes, não disciplinarmente, nas práticas culturais pela via da centralidade da linguagem, atrevendo-se a explorar, a partir dos seus usos. 
A compreensão dos conhecimentos matemáticos como atividades corporalmente encenadas, permeia os arquivos de forma espectral, contudo estes arquivos estão compostos por uma multiplicidade teórica ampla, mas é justamente nessa multiplicidade, que se tem possibilitado efeitos no âmbito epistêmico numa perspectiva decolonial. Uma atitude transgressiva que procurar identificar, na forma em que se mobiliza o conceito de prática, como jogos corporais de cena, que envolvem, não unicamente, os signos sonoros ou impressos que constituem as práticas de falar e escrever, mas que envolvem todas as formas normativamente regradas em que organizamos a vida com propósitos inequívocos (TAMAYO-OSORIO, 2017).

Os textos Bello (2011); Nakamura (2014); Alves (2014) e Tamayo-Osorio (2017) ao estudar como conhecimentos matemáticoS são mobilizados na pesquisa em educação matemática, numa escola de educação básica, uma comunidade caiçara do Rio de Janeiro, e uma comunidade Guna da Colômbia, mostram como conhecimentos matemáticoS são produzidos nessas formas de vida a partir de esquemas teórico-práticos específicos, de maneira que remetem a situações concretas da vida, nas quais seres da natureza interagem para organizar a vida. Esta concepção está inspirada na filosofia de Wittgenstein (1999), na qual a variedade de adjetivações dadas às matemáticaS em diversas formas de vida indicam uma pluralidade de jogos de linguagem, isto é, trata-se de deslocar os usos e significados da Matemática, para além dos aspectos disciplinares e escolares, de maneira a que seja possível ampliar as possibilidades de sentidos de forma contraria à única direção tradicionallogocêntrica referencialmente fixada na escola, isto é, amplia-se a compreensão das matemáticaS como um conjunto diversificado e heterogêneo de práticas performativas. 
O interior significa a existência de uma distinção entre Matemática como um domínio de conhecimento proposicional e conceitual disciplinarmente organizado e, as matemáticaS como um conjunto diversificado e heterogêneo de práticas performativas, o que amplia as significações em uso das matemáticaS em ação, isto é, como conjuntos heterogêneos e dinâmicos de encenações simbólicas regradas do corpo humano, em vista de que, "[...] certamente a matemática é, em certo sentido, uma doutrina, mas também um fazer. [...]” (WITTGENSTEIN, 1979, IF- Parte II, p. 219, itálicos do autor).

No texto de Silva (2012), tais práticas performativas podem ser vistas nas atividades da feira livre, as quais se desenrolam entre o estético e o lúdico, a partir de jogos discursivos que se realizam nas ações, nas reações e nos modos de condução dos sujeitos que participam dessas práticas. A comercialização dos produtos nas práticas envolve jogos que seguem protocolos, compostos pela disposição e cores dos produtos nas bancas, pelos gestos, pelas palavras, meneios e gracejos que são tecidos em um jogo de sedução entre comerciantes e fregueses. A partir de uma visão foucaultiana, poder e saber funcionam como uma engrenagem nesses jogos que estão sempre se movimentando na capacidade que o feirante tem em negociar os significados com os fregueses, fazendo com que os saberes ganhem vida e permaneçam como verdadeiros nas práticas discursivas da feira livre.

\section{Apostas teórico-metodológicas}

$\mathrm{Na}$ leitura dos arquivos identificamos rastros dos efeitos de praticar a pesquisa de forma decolonial no campo da Educação Matemática a partir de uma perspectiva sociocultural como condutas outras para se investigar 
problemas no campo da Educação, isto tem a ver com apostas teóricometodológicas diferenciadas que tentam desafiar paradigmas empíricoverificacionistas de pesquisa acadêmica, alinhados à crítica de Susan Sontag desenvolvida a profundidade em um texto denominado Contra a interpretação, no qual, responsabiliza o projeto hermenêutico-interpretativo não só pela sua pretensão metodologicamente abstracionista, mas também de se eleger o próprio par tensional 'forma versus conteúdo' para orientar metodologicamente pesquisas acadêmicas (MIGUEL, 2015), já que,

A tarefa da interpretação é praticamente uma tarefa de tradução. $\mathrm{O}$ intérprete diz: "Olhe, você não percebe que $\mathrm{X}$ em realidade é — ou significa em realidade - A? Que Y é em realidade B? Que Z é de fato C?". Que situação poderia inspirar este curioso projeto de transformação de um texto? A história nos fornece os elementos de uma resposta. A interpretação aparece primeiramente na cultura da antiguidade clássica mais recente, quando o poder e a credibilidade do mito haviam sido quebrados pela visão "realista" do mundo, introduzida pelo conhecimento científico. (SONTAG, 1966, p. 5).

Os caminhos investigativos das produções até aqui apresentadas se alinham à problematização deste projeto hermenêutico-interpretativo, denominado "moderno" por Sontag pelo fato de tentar evitar esse persistente desejo de interpretar ou explicar ${ }^{13}$, recorrendo a 'descrição' das práticas para entender os problemas de pesquisa do modo em que eles se apresentam para nós, pois "descrever significa um rompimento com as formas de agir dogmaticamente na condução da investigação de um problema de pesquisa" (TAMAYO-OSORIO, 2017, p.40). Este afastamento provoca como efeito que o

\footnotetext{
${ }^{13}$ Para Wittgenstein (2007, p. 194, itálicos nossos) “o empreendimento de uma explicação já é falho, porque só se tem que organizar corretamente o que se sabe, e nada acrescentar, e vem por si mesma a satisfação a que se aspira pela explicação... A explicação não é, aqui, de nenhum modo, o que satisfaz"
} 
interesse do pesquisador não está em procurar elementos causais ou essenciais às falas ou narrativas produzidas no percurso da pesquisa das práticas, em outras palavras,

trata-se, ao contrário, de entendermos que nem descobrimos nem explicamos nada. Porém, podemos significar uma prática sociocultural mediante a descrição das ações e interações das pessoas que as realizam. [...] O descrever é também um jogo de linguagem normativamente orientado. No entanto, nele, não provamos teses (Wittgenstein, 2009, I.F §128), pois nos atemos ao que já sabemos, não "completamos" os fatos, não inferimos nada - nem dedutiva nem indutivamente-, não procuramos algo "novo"; nós apenas estabelecemos relações analógicas de semelhança e diferença entre aspectos manifestos nos jogos de linguagem de diversas formas de vida. (TAMAYO-OSORIO, 2017, p. 41-42. Itálico da autora).

Esta forma de ver e praticar a pesquisa no âmbito da Educação Matemática e da Educação do grupo de pesquisa PHALA, tem provocado outros modos de encenar a escrita, modos outros de lidar com as narrativas e as experiências das vivências das práticas socioculturais como jogos de cena, isto se deve ao fato de que, tanto as pesquisas inspiradas no modo de praticar a filosofia do segundo Wittgenstein, quando aquelas que se inspiram na atitude desconstrucionista derridiana, têm trabalhado, não exclusivamente, com a compreensão das narrativas como jogos de cenas que variam segundo as necessidades da própria pesquisa e dos diversos percursos do pesquisador em relação aos efeitos de sentido da constatação que se coloca como objeto de pesquisa, em palavras de TAMAYO-OSORIO e MARIM (2016, p. 5), 
A constituição de jogos de cenas em um estilo dissertativo-acadêmico constitui o propósito central de textos/pesquisas que não mais imaginam que se possam adentrar em algo além ou independente de práticas de performance da linguagem. Nesse entendimento, a prática de escrita, sobre uma perspectiva wittgensteiniana, concretiza uma possível conciliação da noção derridiana de iterabilidade com a noção austiniana de performatividade (MCDONALD, 2001).

Partindo dessa compreensão da linguagem e da prática da escrita, manifesta-se uma aposta teórico-metodológica diferenciada que tenta desafiar paradigmas empírico-verificacionistas de pesquisa acadêmica, abrindo espaço para que vozes que têm sido silenciadas pelas pesquisas acadêmicas sejam ouvidas com outros instrumentos e sob novos cenários decolonizadores.

Ao apresentarmos esta visão panorâmica de alguns dos efeitos provocados pelas pesquisas tomadas como arquivos para este artigo, é possível evidenciar novos caminhos investigativos para problematizar a Educação (Matemática) e suas relações com a Linguagem e as Práticas culturais, inspirados na proposta filosófica da terapia wittgensteiniana, na desconstrução derridiana e na arqueogenealogia foucaultiana como atitudes que possibilitam descolonizar nossos pensamentos e o saber.

\section{Referências}

D’AMBROSIO, Ubiratan. Etnomatemática, elo entre as tradições e a modernidade. Belo Horizonte: Autêntica, 2001.

LOPEZ BELLO, Samuel Edmundo. Jogos de linguagem, práticas discursivas e produção de verdade: contribuições para a Educação (Matemática) contemporânea. Em 
Zetetike, p. (545-588), Campinas, SP, v. 18, fev. 2011. Disponível em: $<$ https://periodicos.sbu.unicamp.br/ojs/index.php/zetetike/article/view/8646662>

CANDIOTTO, César. A governamentalidade política no pensamento de Foucault. In: Filosofia Unisinos, v.11, n.1, pp. 33-46, 2010.

CASTRO-GÓMEZ, Santiago; Grosfoguel, Ramón. El giro decolonial. reflexiones para una diversidad epistémica más allá del capitalismo global. Bogotá: Siglo del Hombre Editores; Universidad Central, Instituto de Estudios Sociales Contemporáneos y Pontificia Universidad Javeriana, Instituto Pensar, 2007.

DERRIDA, Jacques. Espectros de Marx: o estado da dívida, o trabalho do luto e a nova Internacional. Trad. Anamaria Skinner. Rio de Janeiro: Relume-Dumará, 1994.

DERRIDA, Jacques. Mal de arquivo: uma impressão freudiana. Tradução de Claudia de Moraes Rego. Rio de Janeiro: Relume Dumará, 2001.

DERRIDA, Jacques; STIEGLER, Bernard. Echographies of television: filmed interviews. Tradução de Jennifer Bajorek. Cambridge: Polity Press. 2002.

FOUCAULT, Michel. Segurança, território e população. São Paulo: Martins Fontes, 2008.

MIGUEL, Antonio; VILELA, Denise Silva; DE MOURA, Anna Regina Lanner. Desconstruindo a matemática escolar sob uma perspectiva pós-metafísica de educação. Zetetike, p. (129-206). Campinas, SP, v. 18, fev. 2011. ISSN 2176-1744. Disponível em: <https://periodicos.sbu.unicamp.br/ojs/index.php/zetetike/article/view/8646675/13577>.

MIGUEL, Antonio. A Terapia Gramatical-Desconstrucionista como Atitude de Pesquisa (Historiográfica) em Educação (Matemática). Em: Perspectivas da Educação Matemática - UFMS - v. 8, número temático - 2015. Disponível em: < http://seer.ufms.br/index.php/pedmat/article/view/1466/973 $>$.

MIGUEL, Antonio. Entre Jogos de Luzes e de Sombras: uma agenda contemporânea para a educação matemática brasileira. Em: Revista do Programa de Pós-graduação em Educação Matemática (UFMS), v.9, no. 20. 2016. Disponível em: $<$ http://seer.ufms.br/index.php/pedmat/article/view/2877>.

MONTEIRO, Alexandrina; MENDES, Jackeline R. Etnomatemática como Movimento de Contraconduta na Mobilização de Saberes em Práticas Culturais. GT História da Matemática e Cultura. VI Seminário Internacional de Pesquisa em Educação Matemática, Goiás, 2015.

MONTEIRO, Alexandrina; MENDES, Jackeline R. Movimento de contra-conduta na mobilização de saberes em práticas culturais no campo da Educação Matemática. IV 
Seminario Internacional pensar de otro modo: las nociones de práctica y experiencia como herramientas filosóficas para investigar en educación, Colômbia, 2018.

NAKAMURA, Erica M. (2014). Problematização indisciplinar de práticas socioculturais na formação inicial de professores. (Dissertação de mestrado). Faculdade de Educação, Universidade Estadual de Campinas, Campinas-Brasil.

SILVA, Márcia Lazara Pinheiro. Gracejos e Artimanhas como jogos discursivos na Feira Livre: contribuições para pensar a aprendizagem nas práticas sociais de venda e compra. (Dissertação de mestrado), Universidade São Francisco, Itatiba, 2012.

SONTAG, Susan. Against Interpretation and other essays. New York: Picador, 1966.

TAMAYO-OSORIO, Carolina. Vení, vamos hamacar el mundo, hasta que te asustes: uma terapia do desejo de escolarização moderna. (Tese de doutorado). Universidade Estadual de Campinas, São Paulo. 2017. Disponível em http://repositorio.unicamp.br/jspui/handle/REPOSIP/325354

TAMAYO-OSORIO, Carolina.; BENTO, Marcia Marim. Possibilidade de efeitos de sentido da atitude terapêutico-desconstrucionista em pesquisas da/na educação (matemática). Comunicación en el XII Encontro Nacional de Educação Matemática, São Paulo, Brasil. 2016.

VILELA, Denise. Matemáticas nos usos e jogos de linguagem: Ampliando concepções na Educação Matemática. Tese de Doutorado. Universidade Estadual de Campinas, 2007.

WITTGEnsteIN, Ludwig. Investigações Filosóficas. (Bruni, J.C.,Tard.). São Paulo: Editora Nova Cultural. 1999.

WITTGENSTEIN, L. Observações sobre o Ramo Dourado de Frazer. Trad. ALMEIDA, J.J. Em Suplemento da Revista Digital AdVerbum, v. 2, p. 186-231, 2007.

Recebido em fevereiro de 2018.

Aprovado em outubro de 2018. 